\title{
In Vivo Therapeutic Effect of Triclabendazole + Levamisole on Hydatid Cyst in Rats
}

\author{
Peyman Sadeghi ${ }^{1}$, Yagoob Garedaghi ${ }^{*}$, Mirhadi Khayatnouri ${ }^{3}$, Hosein Hashemzade Farhang ${ }^{4}$, Ramin Kaffash \\ Elahi $^{5}$
}

1Postgraduate Student of Veterinary Medicine, Tabriz Branch, Islamic Azad University, Tabriz, Iran

${ }^{2}$ Department of Parasitology, Tabriz Branch, Islamic Azad University, Tabriz, Iran

${ }^{3}$ Department of Pharmacology, Tabriz Branch, Islamic Azad University, Tabriz, Iran

${ }^{4}$ Department of Pathobiology, Tabriz Branch, Islamic Azad University, Tabriz, Iran

${ }^{5}$ Department of Clinical Sciences, Tabriz Branch, Islamic Azad University, Tabriz, Iran

\begin{abstract}
Introduction: Hydatidosis is a global disease and one of the most dangerous zoonotic diseases which is found in areas where humans, dogs, and herbivores are in close contact with each other.

Methods: In this study, a total of 64 rats were divided into control and case groups, and then 3000 protoscolices were injected into the peritoneal cavity. After 2 months, rats in the case group were given triclabendazole + levamisole at a dose of $6 \mathrm{mg}+4.41$ $\mathrm{mg} / \mathrm{mL}$ orally for 60 days, respectively. Then, after 6 months of infection, the rats of the control and case groups were killed by anesthesia and then an autopsy was performed and the viscera were carefully examined for hydatid cyst infection.

Results: The results showed that in the control group, 3 cysts were observed in the liver, 10 in the kidney, and 88 in the lung. The mean number of hydatid cysts in this group was determined to be 33.6. In the case group, 2 cysts were observed in the liver, 6 in the kidney, and 64 in the lungs. The mean number of hydatid cysts in the viscera was 24 in the case group.

Conclusions: Statistical analysis of the results obtained from the case and control groups showed that the therapeutic efficacy of triclabendazole + levamisole was $31 \%$, which is not enough to treat cases of hydatid cyst.

Keywords: In vivo, Rat, Triclabendazole, Levamisole, Hydatid cyst
\end{abstract}

Received: December 9, 2019, Accepted: December 23, 2019, ePublished: January 1, 2020

\section{Introduction}

Hydatidosis is one of the most dangerous zoonotic diseases worldwide, which is found in areas where humans, dogs, and herbivores are in close contact with each other. Due to the importance of the disease, many studies have been performed on the drug treatment of hydatid cyst in humans and animals, some of which have been successful $(1,2)$. Because triclabendazole + levamisole is one of the old combination drugs, its therapeutic effect on hydatid cyst in laboratory rats was experimentally tested in this study. The first effective drug used against the hydatid cysts caused by Echinococcus in humans was mebendazole. Albendazole is better absorbed and has better penetration into hydatid cysts; therefore, it is generally preferred to mebendazole $(3,4)$. However, none of them have shown significant improvements in most studies. Albendazole is usually administered at the dose of $10 \mathrm{mg}$ per $\mathrm{kg}$ or $400 \mathrm{mg}$ twice daily for 4 weeks and, if necessary, repeated for up to 12 cycles, 2 weeks apart (5). The results of treatment can be best evaluated in humans by ultrasound or magnetic resonance imaging
(MRI) with repetition at intervals of approximately 3 months. It is generally accepted that medication should be started one day (one or more days) before surgery or aspiration and be continued for one month after such procedures $(6,7)$. Praziquantel has somewhat destructive effects on protoscoleces. According to various reports, its combination with albendazole has been associated with good results. In laboratory animals, direct injection of ivermectin into cysts destroyed all protoscoleces $(8,9)$.

\section{Materials and Methods}

In this study, a total of 62 rats were divided into two groups of control and case, and then 3000 protoscolices were injected into the peritoneal cavity of rats. After 2 months, the rats in the case group were treated with triclabendazole + levamisole at a dose of $6 \mathrm{mg}+4.41 \mathrm{mg} /$ $\mathrm{mL}$ orally for 60 days, then after 6 months of infection, the rats in the control and the case groups were killed under anesthesia. Then, an autopsy was performed and the viscera were carefully examined for the presence of hydatid cyst. The number of hydatid cysts formed in the 
internal organs of rats, especially the liver, lungs, and kidneys, was counted. Moreover, the hydatid cyst fluid was aspirated by a syringe and needle head and the hydatid sand was examined under a microscope, indicating that most of the hydatid cysts were fertile.

\section{Results}

The results obtained in this study show that in the control group, 3 hydatid cysts were observed in the liver, 10 in the kidney, and 88 in the lung. The mean number of hydatid cysts in this group was determined to be 33.6 (Table 1).

Additionally, in the case group, only 2 hydatid cysts were observed in the liver, 6 cysts were observed in the kidneys, and 64 hydatid cysts were observed in the lungs (Table 2).

\section{Discussion}

Surgical treatment is still the best standard treatment for hydatid cyst and it is often used to treat human hydatid cysts, while medication prevents the growth of cysts. The drug stops the growth of protoscolices and the germ layers of the cyst, but it does not kill the cells in the epithelium $(10,11)$. Although surgery is still the best treatment, drug treatment with benzimidazole (mebendazole and albendazole) has recently been considered and in some cases, it has been used successfully in humans and animals (12). These drugs are usually prescribed at high doses for a long time. A total of 85 human patients with hydatid cyst were treated with mebendazole as recommended by the World Health Organization. Treatment showed complete success in 8 patients $(9.4 \%)$, relative success in 4 patients $(4.7 \%)$, and failure in 40 patients $(47.1 \%)$. Treatment of another 30 patients with albendazole had better results (13).

When surgical resection is not possible, long-term administration (1 to 6 months) of mebendazole at high

Table 1. Number of Hydatid Cyst in the Control Group

\begin{tabular}{lccc}
\hline Infected Organ & $\begin{array}{c}\text { Number of Hydatid } \\
\text { Cyst }\end{array}$ & $\begin{array}{c}\text { Color of Hydatid } \\
\text { Cyst }\end{array}$ & $\begin{array}{c}\text { Diameter of Hydatid } \\
\text { Cyst }\end{array}$ \\
\hline Liver & 3 & White & $2-6 \mathrm{~mm}$ \\
Kidney & 10 & White & $5-7 \mathrm{~mm}$ \\
Lung & 88 & White & $4-9 \mathrm{~mm}$ \\
$\begin{array}{l}\text { Mean number of } \\
\text { hydatid cysts }\end{array}$ & 33.6 & - & - \\
\hline
\end{tabular}

Table 2. Number of Hydatid Cyst in the Case Group

\begin{tabular}{lccc}
\hline Infected Organ & $\begin{array}{c}\text { Number of Hydatid } \\
\text { Cyst }\end{array}$ & $\begin{array}{c}\text { Color of Hydatid } \\
\text { Cyst }\end{array}$ & $\begin{array}{c}\text { Diameter of Hydatid } \\
\text { Cyst }\end{array}$ \\
\hline Liver & 2 & White & $2-4 \mathrm{~mm}$ \\
Kidney & 6 & White & $4-5 \mathrm{~mm}$ \\
Lung & 64 & White & $2-6 \mathrm{~mm}$ \\
$\begin{array}{l}\text { Mean number of } \\
\text { hydatid cysts }\end{array}$ & 24 & - & - \\
\hline
\end{tabular}

doses (40 mg/kg in 24 hours) can have different successful results. In humans, due to the long period of drug use, for example, about 4 months, consumers get bored or do not use it completely. Therefore, drug treatment is not very successful in humans. Only in special circumstances in humans such as the inability of the patient and the patient's age, medical help is sought. Additionally, the drug is prescribed after surgery to prevent the spread of the disease $(10,14)$. The World Health Organization recommends the use of mebendazole for treatment. In addition, albendazole has given good results. In cases where surgery is not possible due to the patient's general condition, the size of the cysts, or their position, treatment with mebendazole may be helpful $(5,8)$.

Pulmonary cysts appear to show the best response, liver cysts are less responsive, and cysts in other organs, especially the brain, bone, and eye, have a poor response to the drug. Doses of 50 to $150 \mathrm{mg} / \mathrm{kg} / \mathrm{d}$ for 3 months are probably the least effective, and many patients require repeated courses. Hydatid cysts appear to be well protected against the host's immune system, and attempts to stimulate host immunity by injecting hydatid cyst fluid, which has been widely used previously, do not appear to be effective. In contrast, direct injection of serum containing the infected host complement into cysts can destroy them and it is recommended for the treatment of unresectable cysts by surgery $(11,15)$.

According to a study on the combination of drug therapy and surgery for liver hydatidosis in men, the recurrence rate has decreased and in recent years, treatment with albendazole has been started before and after surgery. This study shows the results of the treatment of 331 patients with hydatidosis. The results of this combination of surgery and medication show that the use of albendazole before and after surgery is good. Simultaneous drug treatment and surgery can reduce the number of cysts, stop their growth, and reduce their recurrence after surgery $(3,16)$.

In a study on 54 patients with alveolar cysts, Eckert (17) showed that long-term treatment with mebendazole improved the disease or stopped its progression in 38 of them $(70.4 \%)$. These changes can indicate that the parasite has stopped growing.

Horton et al (1) reported that the efficacy of albendazole in the treatment of hydatid cyst was $46 \%$ in rats. Kashmiri et al (2) reported an efficacy of 39\% for triclabendazole in the treatment of pulmonary hydatid cyst. Siles-Lucas (3) reported that the efficacy of triclabendazole and levamisole was $37 \%$ in the treatment of pulmonary hydatid cysts, $41 \%$ in the treatment of hepatic hydatid cysts, and $28 \%$ in the treatment of renal hydatid cysts. Sylvia et al (18) studied the effect of dithiazanine iodide on the larval stage of Echinococcus in mice. Tsukasa et al (19) investigated the effect of albendazole on human hydatid cyst. Polat et al (6) investigated the effect of albendazole and povidone-iodine on hydatid cyst protoscolices in vivo 
and in vitro. The viability of protoscoleces was detected as $95 \%$.

\section{Conclusion}

Results of this study indicated that administration of Triclabendazole + Levamisole for the treatments of hydatid cyst is not sufficient in rats.

\section{Conflict of Interests}

The authors declare that they have no conflict of interests.

\section{Ethical Issues}

In this research, ethical considerations have been fully observed.

\section{Financial Support}

This research was conducted with the support of theVice Chancellor for Research and Technology of the Islamic Azad University, Tabriz, Iran.

\section{Acknowledgments}

This study was conducted as a doctoral dissertation at the Islamic Azad University, Tabriz, Iran

\section{References}

1. Horton RJ. Chemotherapy of Echinococcus infection in man with albendazole. Trans R Soc Trop Med Hyg. 1989;83(1):97102. doi: 10.1016/0035-9203(89)90724-4.

2. Keshmiri $\mathrm{M}$, Baharvahdat $\mathrm{H}$, Fattahi $\mathrm{SH}$, et al. A placebo controlled study of albendazole in the treatment of pulmonary echinococcosis. Eur Respir J. 1999;14(3):503-7. doi: 10.1034/j.1399-3003.1999.14c05.x.

3. Siles-Lucas M, Casulli A, Cirilli R, Carmena D (2018) Progress in the pharmacological treatment of human cystic and alveolar echinococcosis: Compounds and therapeutic targets. PLoS Negl Trop Dis 12(4): e0006422. doi:10.1371/journal. pntd.0006422.

4. Richards KS, Morris DL. Effect of albendazole on human hydatid cysts: an ultrastructural study. HPB Surg. 1990;2(2):105-12. doi: 10.1155/1990/47243.

5. Sakamoto T. Relationships between anthelmintic effects of drugs against Echinococcus multilocularis in vitro and in vivo. Memoirs of the Faculty of Agriculture, Kagoshima University. 1979;15:115-23.

6. Polat E, Aslan M, Cakan H, Saribas S, Ipek T, Kocazeybek B. The effects of albendazole and povidone iodine for hydatid cysts protoscoleces, In-vitro and-vivo. Afr J Microbiol Res.
2009;3(11):743-6. doi: 10.5897/ajmr.9000694.

7. Soulsby EJL. Helminths, Arthropods and Protozoa of Domesticated Animals. London: Bailliere Tindall; 1986.

8. Rokni MB. Echinococcosis/hydatidosis in Iran. Iran J Parasitol. 2009;4(2):1-16

9. Brunetti E, Kern P, Vuitton DA. Expert consensus for the diagnosis and treatment of cystic and alveolar echinococcosis in humans. Acta Trop. 2010;114(1):1-16. doi: 10.1016/j. actatropica.2009.11.001.

10. Norouzi R. A review on most nanoparticles applied against parasitic infections. J Biol Today's World. 2017;6(10):196203. doi: 10.15412/j.jbtw.01061003.

11. Sharafi SM, Sefiddashti RR, Sanei B, Yousefi M, Darani HY. Scolicidal agents for protoscolices of Echinococcus granulosus hydatid cyst: review of literature. J Res Med Sci. 2017;22:92. doi: 10.4103/jrms.JRMS_1030_16.

12. Mahmoudvand $H$, Fasihi Harandi $M$, Shakibaie $M$, Aflatoonian MR, ZiaAli N, Makki MS, et al. Scolicidal effects of biogenic selenium nanoparticles against protoscolices of hydatid cysts. Int J Surg. 2014;12(5):399-403. doi: 10.1016/j. ijsu.2014.03.017.

13. Malekifard F. Solicidal effect of the gold nanoparticle on protoscoleces of hydratid cyst in vitro. The Journal of Urmia University of Medical Sciences. 2017;28(2):130-7.

14. Wang T, Van Steendam K, Dhaenens M, Vlaminck J, Deforce $\mathrm{D}$, Jex AR, et al. Proteomic analysis of the excretory-secretory products from larval stages of Ascaris suum reveals high abundance of glycosyl hydrolases. PLoS Negl Trop Dis. 2013:7(10):e2467. doi: 10.1371/journal.pntd.0002467.

15. Garedaghi Y, Bahavarnia S. Seroepidemiological study of hydatid cyst by ELISA method in East-Azarbaijan province (2009). Iran JEpidemiol. 2011;7(2):25-9.

16. Pan W, Hao WT, Shen YJ, Li XY, Wang YJ, Sun FF, et al. The excretory-secretory products of Echinococcus granulosus protoscoleces directly regulate the differentiation of B10, B17 and Th17 cells. Parasit Vectors. 2017;10(1):348. doi: 10.1186/ s13071-017-2263-9.

17. Eckert J, Deplazes P. Biological, epidemiological, and clinical aspects of echinococcosis, a zoonosis of increasing concern. Clin Microbiol Rev. 2004;17(1):107-135. doi:10.1128/ cmr.17.1.107-135.2004.

18. Richards KS, Morris DL. Effect of albendazole on human hydatid cysts: an ultrastructural study. HPB Surg. 1990;2(2):105-113. doi: 10.1155/1990/47243.

19. SAKAMOTO T. Relationships between Anthelmintic Effects of Drugs against Echinococcus multilocularis. Mem. Fac. Agr. Kagoshima Univ1979;15:115-23

(C) 2020 The Author(s); This is an open-access article distributed under the terms of the Creative Commons Attribution License (http:// creativecommons.org/licenses/by/4.0), which permits unrestricted use, distribution, and reproduction in any medium, provided the original work is properly cited. 